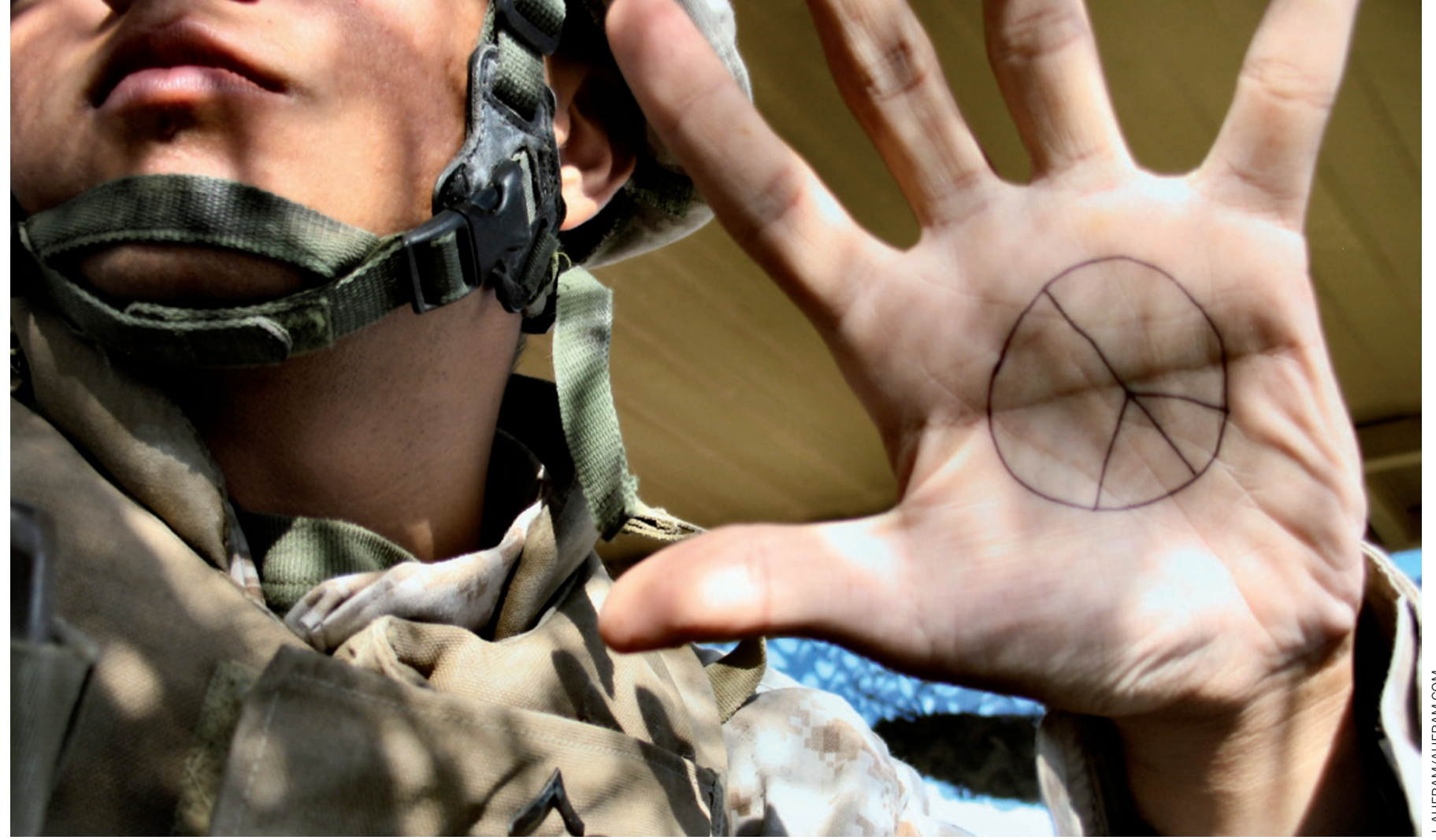

Despite multiple conflicts and two world wars in the past century, societal evolution has led to an overall decline in violence and death.

PSYCHOLOGY

\title{
A farewell to arms
}

\section{Martin Daly explores Steven Pinker's treatise on the taming of human aggression.}

$\mathrm{W}$

ars and genocides, murder and mayhem - violent victimization seems to be rising inexorably. But the massive coverage of these horrific phenomena masks an important truth. On average, our chances of being assaulted or killed have been falling for centuries. In The Better Angels of Our Nature, psychologist Steven Pinker reviews the evidence for this stunning historical trend, and tries to explain it.

In what is arguably his most ambitious work yet, Pinker includes figures showing declining rates of homicide, warfare, acts of terrorism, child abuse and other forms of violence over various timescales. But there is more here than statistics. Pinker's narrative moves from prehistory, through the social and intellectual revolutions of the eighteenth and nineteenth centuries, to current findings on mind, brain and behaviour. Citing the insights and scholarship of not just the usual gang of psychologists, neuroscientists and evolutionary biologists, but also of historians, philosophers and every sort of social scientist, he concludes that societal evolution has reduced the incentives to commit violence and changed modern sensibilities.

The intellectual hero of Pinker's story - a

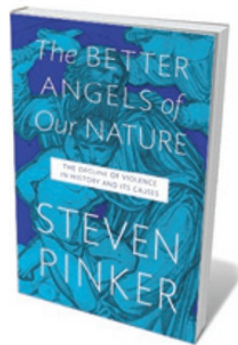

The Better Angels of Our Nature: Why Violence Has Declined/The Decline of Violence in History and Its Causes

STEVEN PINKER Viking/Allen Lane: 2011. 832 pp. $\$ 40 / £ 30$ Leviathan) that could monopolize legitimate violence and arbitrate disputes, reducing the need for private retribution. The other was the rise of 'gentle commerce', whereby mutual gains from trade created a common purpose.

After introducing and defending Elias's ideas, Pinker applies them to history. Reviewing the 'humanitarian revolution', he describes how, in Europe and elsewhere, the xenophobia that was once ubiquitous became untenable over several centuries. Torture, execution at whim and slavery also moved from the mainstream to the marginal.

Pinker then makes the case that warfare has long been in decline - and may be facing extinction. Scholarly analysis of armed conflicts and their death tolls apparently demonstrates that a bias towards recency has blinded us to this startling truth: that both the incidence of war and the death rate it imposes have been shrinking. Even in the twentieth century, with its two world wars, these numbers were lower than in previous centuries. And they have kept falling. Pinker chronicles the 'rights revolutions' of the twentieth century: struggles for civil rights, women's rights, children's rights, gay rights and animal rights, with thought-provoking discussion of the rapidly changing sensibilities that accompanied them. His skill in mixing quantitative analysis with illustrative examples, apt quotations and the occasional joke makes these chapters page-turners.

Pinker then turns his attention to the links between the history of violence and his view - familiar from his previous books - that the evolved human psyche is a bundle of special-purpose 'faculties', including certain "inner demons" and "better angels". He reviews what neuroscience has to say about aggression and empathy, and what social psychologists have discovered about the elicitors of sympathy, punitiveness and other mental states. He concludes with a surprising, force-

ful argument for a go.nature.com/nbrlsp
DNATURE.COM For Steven Pinker's views on declining violence: 
historical rise in human reasoning ability, which he believes may provide a counterweight to parochialism and intergroup hostility.

Any thoughtful reader of this wideranging treatise will find nits to pick. I am not persuaded that because 1960 s counterculture glorified selfish impulsiveness ('just do it'), it was responsible for a small increase in the US homicide rate. The counterculture was largely about forsaking violence ('make love, not war'). Neither am I persuaded by Pinker's explanations for the decline in US homicide in the 1990s; in my view, he too hastily dismisses the possible relevance of demographic changes, and too credulously accepts that increased police presence and incarceration were important.

Pinker's biggest slip, in my view, concerns the relevance of income inequality, which has been the most successful predictor of variability in homicide rates between different places. Pinker gives it one brief paragraph, waving it off on the grounds that the standard index of income inequality was going up during the 1990s in the United States while crime rates were falling, and was at a nadir in 1968 when crime was "soaring". The trouble with this argument is that there is no reason to expect simultaneous short-term vicissitudes of income inequality and homicide; any effect of the former on the latter is surely mediated by people's cumulative experiences over their lifetimes. And it is ironic that despite Pinker's dismissal, the big historical story he tells - stressing the decline of despotism and marauding and the rise of democratic governments - is itself a tale of decreasing inequality.

Pinker closes with a rousing defence of modernity. Ultimately, his explanation for the decline of violence is Elias's - that the synergistic impacts of Leviathan and gains from trade have created a civilizing process that has diminished the utility of violence and, hence, its appeal. But he elaborates on this with an engaging game-theoretical twist (the "Pacifist's Dilemma"), and more-up-to-date psychology than Elias would have been able to muster. The Better Angels of Our Nature is a lively, fascinating read and a remarkable scholarly achievement that deserves to be studied and debated by many social scientists, concerned citizens and policy-makers.

Martin Daly is professor of psychology in the Department of Psychology,

Neuroscience and Behaviour, McMaster University, Ontario L8S 4K1, Canada. e-mail:daly@mcmaster.ca

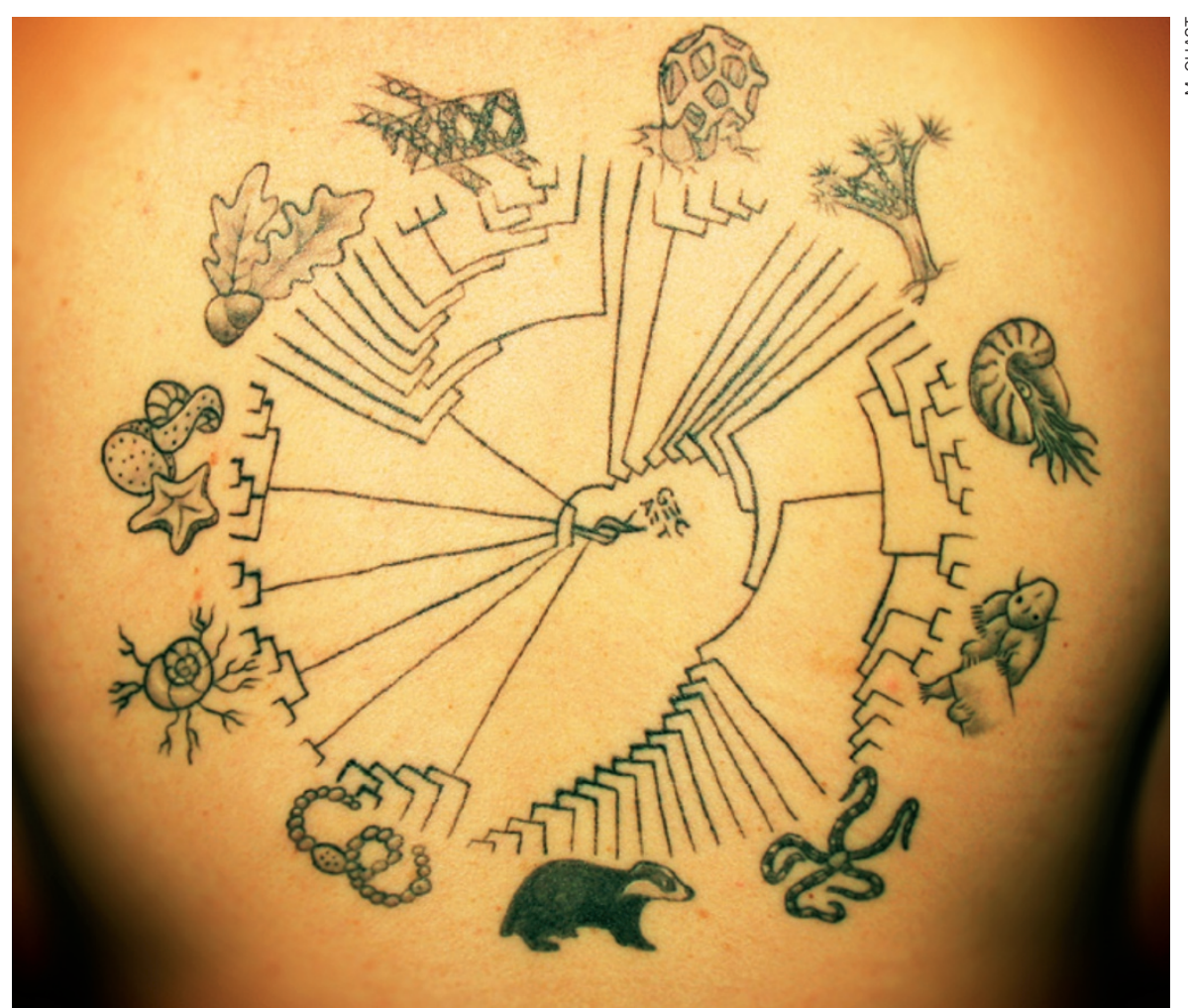

A biology graduate's back carries a reminder that DNA gave rise to all the biodiversity on Earth.

\section{SOCIOLOGY}

\section{The illustrated scientist}

\section{Margo DeMello is fascinated by the evocative tattoo culture among different 'tribes' of scientists.}

$\mathrm{T}$

attoos were taboo until recently in the West - seen by most as the barbaric practice of marginalized or underworld groups. Now, tattooing is undergoing a renaissance. Almost mainstream in Europe and North America, tattoos are becoming ever more artistically sophisticated and personally meaningful.

Carl Zimmer's beautiful new book, Science Ink, focuses on tattoo culture among scientists, both amateur and professional. Zimmer, himself a tattoo-free science writer, began asking researchers to send photographs of their science-related tattoos to The Loom, his blog for Discover Magazine, in August 2007. These, and the stories behind them, evolved into Science Ink.

The book is broadly organized by discipline, featuring photos of tattoos themed to each - astronomy, chemistry, evolution, natural history, neuroscience and palaeontology. The scientists are using their body art to mark their standing as members of these 'tribes': so you see stars on astronomers, bacteria on biochemists, insects on entomologists and equations and symbols on mathematicians. And

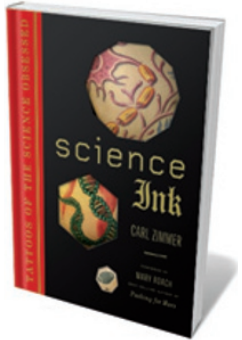

Science Ink: Tattoos of the Science Obsessed CARL ZIMMER Sterling: $2011.288 p p$. $\$ 24.95, £ 16.99$

the tattoos are simple line drawings. Many are colourful and stunningly detailed - such as the elaborate picture on a mathematician's back of a microscope and the usually hidden world it reveals.

These decorated scientists join a tradition that is both venerable and near universal. The earliest evidence for tattooing dates back to Neolithic Eurasia. From there it probably spread from the Middle East to the Pacific 